ARTÍCULOS ORIGINALES Rev Chil Salud Pública 2014; Vol 18 (1): 87-94
Cristóbal Pizarro Facultad de Odontología Universidad de Valparaíso. cpizarrovallejos@gmail.com

Daniela Valenzuela Facultad de Odontología Universidad de Valparaíso.

\section{NIVEL DE CONOCIMIENTO EN SALUD ORAL DEL EQUIPO DE SALUD EN CENTROS DE ATENCIÓN PRIMARIA DE LA REGIÓN DE VALPARAÍSO}

\author{
LEVEL OF ORAL HEALTH KNOWLEDGE OF THE HEALTHCARE TEAM IN \\ PRIMARY HEALTH CARE CENTERS IN THE VALPARAISO REGION
}

\section{RESUMEN}

Introducción: En el modelo actual de Salud Familiar, el equipo de salud debe poseer conocimientos transversales respecto de las primeras etapas del ciclo vital con el control de embarazadas y posteriormente control de niño sano, los que se encuentran estandarizados en el documento Pauta de evaluación buco-dentaria establecida por Minsal en 2007.

Objetivo: Evaluar el nivel de conocimiento en salud oral del equipo de salud en los centros de atención primaria de la quinta región.

Materiales y métodos: El diseño de este estudio es de corte transversal. La muestra se obtuvo de todos los centros de salud que ejercen atención primaria en la quinta región. De un total de 77 consultorios, se seleccionaron aleatoriamente 35 de manera proporcional entre las tres redes asistenciales, de los cuales 14 corresponden al Servicio de Salud Valparaíso - San Antonio (SSVSA), 17 al Servicio de Salud Viña del Mar - Quillota (SSVQ) y cuatro al Servicio de Salud Aconcagua (SSA).

Cada centro contempla un equipo de salud compuesto por un médico, enfermero(a), matrón(a), nutricionista y técnico paramédico, a los cuales se les aplicó un cuestionario para la obtención de la información.

Resultados: Se evidenció que el equipo de salud de los centros de atención primaria de la quinta región presenta un $49 \%$ de respuestas afirmativas $y / o$ correctas.

Discusión: El nivel de conocimiento de salud oral del equipo de salud de los centros de atención primaria de la quinta región es insuficiente.

Palabras clave: equipo de salud, atención primaria, salud familiar. 


\section{ABSTRACT}

Introduction: In the current model of family bealth, the bealthcare team must possess comprebensive knowledge regarding the early stages of the life cycle, care of pregnant women, and subsequently, healthy children, which are standardized in the in the oral health evaluation guidelines of 2007, by the Ministry of Health.

Objective: Assess the level of oral health knowledge of the healthcare team in public primary bealthcare centers in the fifth region, Valparaiso.

Materials and Methods: The design of this study is cross-sectional. The sample was obtained from all bealth centers offering primary care in the fifth region. From a total of 77 clinics, 35 were randomly selected in equal proportions from 3 bealth services, of which 14 belong to the Valparaiso - San Antonio Health Service (SSVSA), 17 to the Viña del Mar - Quillota Health Service (SSVQ) and 4 to the Aconcagua Health Service (SSA).

Each center has a bealthcare team consisting of a doctor, nurse, midwife, nutritionist and paramedic, and a questionnaire was filled out by each to obtain the data for this study.

Results: It was shown that the healthcare team of the primary health care centers in the fifth region had $49 \%$ affirmative or positive answers.

Discussion: The level of oral health knowledge of the healthcare team in public primary bealth care centers in the fifth region is insufficient.

Key words: healthcare team, primary health care, family health.

\section{INTRODUCCIÓN}

El sistema de salud pública en Chile se desarrolla esencialmente en un proceso de continuidad de la atención en torno al usuario, a través de la red asistencial, la que se operativi$\mathrm{za}$ en distintos niveles de capacidad resolutiva, de atención primaria, de especialidades, de hospitalización y de urgencia (1).

La conformación de la red asistencial de cada servicio de salud, contempla al "conjunto de establecimientos asistenciales públicos que forman parte del Servicio, los establecimientos municipales de Atención Primaria de Salud (APS) de su territorio y los demás establecimientos públicos o privados que mantengan convenios con el Servicio de Salud respectivo para ejecutar acciones de salud, los cuales deberán colaborar y complementarse entre sí para resolver de manera efectiva las necesidades de salud de la población” (2).

La APS es el eje del sistema que interactúa fuertemente con la comunidad y con otros sectores de la salud, basándose en lo propuesto en la declaración de Alma-Ata, donde se hace indispensable para el pueblo la promoción y prevención en salud (3).

Con el propósito de cumplir con esta interacción y de llevar a cabo un modelo integral en la atención primaria, la reforma de la salud plantea un modelo de gestión en red basado en el fortalecimiento de estos centros de atención con el Modelo de Salud Familiar, transformando dicha atención en un proceso más ambulatorio, de acuerdo a las necesidades locales.

La APS contempla los tres niveles de prevención que se ven reflejados en primer lugar en sus servicios de promoción y prevención, luego en tratamiento y finalmente en rehabilitación que otorga a la comunidad. Respecto al primer nivel, comienza desde las primeras etapas del ciclo vital con el control de embarazadas y posteriormente al control de niño sano a cargo de un equipo de salud multidisciplinario, que nace a partir de la salud familiar.

Este trabajo en equipo coordinado facilita el diseño de estrategias coherentes con los principios fundamentales del Modelo de 
Salud Familiar, y que permite un desarrollo sustentable en el tiempo (4). La comunicación entre los equipos debe ser cercana, en función de dar respuestas concretas a las demandas de salud, de manera que no se produzca una superposición de roles, o una multiplicación o descoordinación en las intervenciones (5).

Con el fin de establecer un conocimiento básico y un criterio unificado, así como también facilitar la capacitación y la coordinación que se debe establecer entre el equipo odontológico y el equipo de salud, que realiza el Control de Salud del Niño, en los establecimientos de atención primaria de salud (6) es que Minsal creó la Norma de Actividades Promocionales y Preventivas Específicas en la Atención Odontológica Infantil en 1998, la cual fue reeditada en la Pauta de Evaluación Buco-dentaria en el año 2007. Dichos trabajos pretenden determinar tempranamente los riesgos individuales de salud bucal del niño, para adoptar estrategias y establecer los cuidados necesarios (6).

Los documentos antes mencionados responden al actual modelo de atención centrado en la familia, considerando que el equipo de salud de atención primaria tiene un contacto más frecuente con las madres que los odontólogos. Hay que recordar que el primer control odontológico es a los 2 años, es muy importante que ellos contribuyan a la salud integral del niño (6). De ahí es que surge la interrogante acerca de qué conocimientos sobre los contenidos teóricos de esta pauta tiene el personal médico, enfermero(a), nutricionista, matrón(a) y técnico en enfermería de nivel superior (TENS).

El objetivo de este estudio es, por consiguiente, evaluar el nivel de conocimiento de salud oral del equipo de salud en los centros de atención primaria públicos de la región de Valparaíso.

\section{MATERIALES Y MÉTODOS}

El diseño de este estudio es de corte transversal. La población corresponde al total de los equipos de salud de los centros de atención primaria públicos de la región de Valparaíso.
Muestra y unidad de estudio. La región de Valparaíso cuenta con 77 establecimientos de atención primaria estatal, los cuales pueden ser agrupados en tres servicios de salud, que corresponden a Servicio de Salud de Valparaíso - San Antonio (SSVSA) con 26 centros de atención, Viña del Mar - Quillota (SSVQ) con 36 centros, y el Servicio de Salud Aconcagua (SSA), con 15 centros de atención, que en su totalidad articulan la red asistencial de la región de Valparaíso.

La presente selección fue realizada mediante muestreo probabilístico de tipo conglomerado de asignación proporcional, obteniéndose la siguiente distribución de centros por red asistencial: 14 centros integrados en el SSVSA, 17 en SSVQ y cuatro en SSA.

Cada centro de atención primaria público seleccionado corresponde a una unidad de estudio compuesta por un médico, un enfermero(a), un matrón(a), un nutricionista y un TENS, el equipo pediátrico según la Pauta de 2007, por lo que los 35 centros de salud equivalen a 35 equipos de salud. Los centros de atención que funcionan con el mismo equipo de salud, son válidos como una única unidad de estudio.

Procedimientos. Para la obtención de la información, el equipo de salud respondió un cuestionario que permitió medir su nivel de conocimiento para llegar a una evaluación inicial. Este instrumento se aplicó durante los meses de mayo a julio de 2012 y consistió en 30 preguntas de alternativa y desarrollo, en donde se abordaron los siguientes tópicos: acceso, anatomía, higiene y uso de flúor, alimentación, patología, malos hábitos y traumatismo dento-alveolar (TDA) y reconocimiento.

Este instrumento previamente fue aplicado a 18 estudiantes de las carreras de Odontología, Medicina, Nutrición y dietética, Obstetricia, Enfermería de la Universidad de Valparaíso y TENS del Duoc UC.

Cada participante de la investigación, previa explicación verbal, leyó y firmó el consentimiento informado del presente estudio. A continuación se les entregó un instructivo que explicaba cómo responder el cuestionario. Los evaluadores estuvieron presentes 
durante el tiempo que demoraron en completarlo, con el propósito de responder consultas y eliminar cualquier sesgo por parte del consultado.

Análisis estadístico. Para el análisis estadístico se utilizó el programa estadístico SPSS 15.0 para Windows.

Para la calificación del nivel de conocimiento en salud oral de la unidad de estudio, se ocupó la conversión de los porcentajes de respuestas correctas obtenidos a la escala de 1.0 a 7.0 utilizada en Chile, donde 7.0 equivale a 'sobresaliente', 6.0 a 'muy bueno', 5.0 a 'bueno', 4.0 a 'suficiente', 3.0 a 'insuficiente', 2.0 a 'deficiente' y 1.0 'malo' (7).

\section{RESULTADOS}

La muestra de un total de 172 participantes en este estudio estuvo constituida por 34 médicos, 35 enfermeros(as), 34 matrones(as), 34 nutricionistas y 35 TENS. De ellos, 142 pertenecen al género femenino, lo que corresponde al 82,6\% y solo 30 al masculino (17,4\%).

En el primer ítem, referente a anatomía dentaria, la pregunta con menor porcentaje de respuestas correctas para los distintos estamentos fue la cantidad de dientes temporales que presenta un niño (20 dientes), donde matrón(a), nutricionista y TENS promedian bajo el $30 \%$ de respuestas correctas.

Tabla 1. Distribución (\%) de respuestas correctas referentes a 'anatomía dentaria' por estamento.

\begin{tabular}{lccccc}
\hline \multirow{2}{*}{ Ítem de Anatomía } & \multicolumn{5}{c}{ Estamento } \\
& Médico & Enfermero(a) & Matrón(a) & Nutricionista & TENS \\
Cantidad dientes temporales & 38,2 & 68,6 & 29,4 & 26,5 & 25,7 \\
Edad erupción primer diente & 64,7 & 77,1 & 61,8 & 73,5 & 57,1 \\
Tipo de diente & 88,2 & 97,1 & 97,1 & 97,1 & 68,6 \\
Promedio & 63,7 & 80,9 & 62,8 & 65,7 & 50,5 \\
\hline
\end{tabular}

Tabla 2. Distribución (\%) de respuestas correctas correspondientes a 'higiene bucal' y 'uso de flúor' por estamento.

\begin{tabular}{lccccc}
\hline Ítem de Higiene & & & Estamento & & \\
& Médico & Enfermero (a) & Matrón(a) & Nutricionista & TENS \\
Higiene antes 6 meses & 64,7 & 94,3 & 82,4 & 70,6 & 85,7 \\
Instrumento higiene antes 6 meses & 29,4 & 82,9 & 67,6 & 44,1 & 54,3 \\
Materiales de higiene en niños & 85,1 & 88,7 & 90,9 & 72,8 & 82,9 \\
Técnica de Fones & 41,2 & 28,6 & 29,4 & 47,1 & 40 \\
Uso pasta en niños & 85,3 & 62,9 & 85,3 & 67,6 & 51,4 \\
Edad comienzo uso pasta & 32,4 & 54,3 & 38,2 & 38,2 & 45,7 \\
Cantidad de pasta & 47,1 & 62,9 & 55,9 & 50 & 48,6 \\
Momento de cepillado & 17,6 & 20 & 23,5 & 5,9 & 20 \\
Quién debe cepillar & 76,5 & 85,7 & 79,4 & 85,3 & 77,1 \\
Concentración de flúor & 23,5 & 22,9 & 20,6 & 44,1 & 22,9 \\
Promedio & 50,3 & 60,3 & 57,3 & 52,6 & 52,9 \\
\hline
\end{tabular}


Con respecto al ítem sobre higiene dental, las preguntas con menor porcentaje de respuestas acertadas, en forma transversal fueron: Conocimiento de técnica de cepillado de Fones, en qué momento del día debe realizarse el cepillado (después de cada comida y antes de dormir) y concentración de flúor que debe tener una pasta dental infantil (500 $\mathrm{ppm})$, en donde todos los estamentos de funcionarios estuvieron por debajo del $50 \%$ de respuestas correctas.

Dentro del ítem sobre alimentación, en la pregunta referente a edad de retiro del biberón nocturno (18 meses), los estamentos promediaron un bajo porcentaje de respuestas correctas, donde los nutricionistas se muestran con un $8,8 \%$ de respuestas acertadas. Con respecto a la edad de comienzo del consumo de alimentos sólidos (2 años y 6 meses), el grupo de TENS se encuentra con un 8,6\% de respuestas correctas.
En el siguiente ítem fueron agrupadas las preguntas en torno a reconocimiento de malos hábitos y patologías y las consecuencias y conductas a seguir frente a un TDA. En esta sección, por cada pregunta debían reconocer 3 o 4 alternativas correctas. Respecto a las preguntas de reconocimiento de un mal hábito oral y cuáles son las conductas a seguir frente a un TDA, los funcionarios se encuentran bajo el $42 \%$ de respuestas correctas y el estamento nutricionista se presenta solo con un $17 \%$.

En el último ítem se seleccionaron cinco imágenes en las cuales los funcionarios debían identificar, en primer lugar, si la situación que se presentaba era normal o anormal, y, en segundo lugar, describir en palabras simples lo que observaban por cada imagen. En la primera de ellas se mostraba una situación de maloclusión, hipoplasia, caries y mala higiene. En la segunda imagen, la presencia de dentición mixta, mala higiene, maloclusión e

Tabla 3. Distribución (\%) de respuestas correctas referentes a ‘alimentación’ por estamento.

\begin{tabular}{|c|c|c|c|c|c|}
\hline \multirow{2}{*}{ Ítem de Alimentación } & \multicolumn{5}{|c|}{ Estamento } \\
\hline & Médico & Enfermero (a) & Matrón(a) & Nutricionista & TENS \\
\hline Uso azúcar en el biberón & 82,4 & 80 & 92,2 & 76,2 & 100 \\
\hline Término lactancia materna exclusiva & 64,7 & 65,7 & 85,3 & 88,2 & 77,1 \\
\hline Retiro biberón nocturno & 14,7 & 25,7 & 17,6 & 8,8 & 11,4 \\
\hline Edad uso de líquidos en vaso & 41,2 & 25,7 & 44,1 & 35,7 & 40 \\
\hline Definición dieta cariogénica & 79,4 & 80 & 81,4 & 88,2 & 45,7 \\
\hline Consumo alimentos sólidos & 35,3 & 11,4 & 11,8 & 20,6 & 8,6 \\
\hline Promedio & 52,9 & 48 & 55,4 & 52,8 & 47,1 \\
\hline
\end{tabular}

Tabla 4. Distribución (\%) de respuestas correctas referentes a 'patología', 'malos hábitos' y 'TDA' por estamento

\begin{tabular}{lccccc}
\hline $\begin{array}{l}\text { Variables de Patología, } \\
\text { Malos Hábitos y TDA }\end{array}$ & Estamento & & & & \\
& Médico & Enfermero (a) & Matrón(a) & Nutricionista & TENS \\
Reconocimiento de mal hábito & 41,1 & 31,4 & 41,1 & 17,6 & 14,3 \\
Reconocimiento de patología oral & 50,1 & 48,5 & 26,4 & 61,8 & 57,1 \\
Consecuencia de TDA & 50 & 60 & 32,4 & 41,2 & 62,9 \\
Conducta frente a TDA & 32,3 & 34,3 & 23,5 & 17,5 & 28,6 \\
Promedio & 43,3 & 43,5 & 30,8 & 34,5 & 40,7 \\
\hline
\end{tabular}


interposición lingual; en la tercera imagen, la patología de frenillo lingual corto; en la cuarta imagen, una niña con mal hábito de succión digital, y en la quinta y última imagen se mostraba una mano cuyas uñas indicaban mal hábito de onicofagia. En las imágenes 1 y 2 de manera transversal, es posible observar cifras de $0 \%$ de respuestas correctas.

\section{DISCUSIÓN}

Luego de realizar una evaluación de los resultados obtenidos con el instrumento de medición, es importante destacar que todos los estamentos poseen un conocimiento insuficiente, tomando como referencia la escala de calificación anteriormente presentada, en lo que respecta a anatomía dentaria. Es posible observar que, a excepción de los enfermeros, el equipo de salud, en su mayoría, no sabe cuántos dientes debería tener un infante, por lo que no podrían llegar a detectar una situación anómala en este aspecto.

Podemos considerar el ítem de higiene como uno de los más importantes respecto de la prevención de la patología bucal de mayor prevalencia en Chile: la caries. Esta se inicia a edades muy tempranas, lo que queda demostrado en los estudios de diagnóstico en
Salud Bucal de niños, observándose que a los 2 años, existe un $83 \%$ de niños sin historia de caries; a los 4 años, un $51,98 \%$ de niños sin historia de caries (8), y a los 6 años un 29,64\% de niños sin historia de caries (9). Las causas de esta patología son evitables con medidas de autocuidado, tal como hábito de cepillado, que pueden ser aplicadas desde el primer año de vida (10). Por esta razón, la educación para la salud cumple un papel fundamental en la prevención de las enfermedades bucales, así como en el mantenimiento de individuos saludables.

Analizando las preguntas de este último ítem, todos los estamentos reconocen que los niños deben ser higienizados desde su nacimiento, pero desconocen cómo y en qué momento deben realizarlo, así como también desde cuándo deben comenzar con el uso de pasta dental, y qué concentración de flúor debe tener. Solo disponiendo de esta información se puede esperar un cambio en los índices de patologías bucodentarias en la población infantil $\mathrm{y}$, por ende, en la futura población adulta (10).

Hoy se ha determinado claramente cuáles son las principales causas de este daño precoz en la dentición infantil. Las caries se producen por el consumo habitual de fórmulas lácteas con azúcar, bebidas gaseosas, jugos

Tabla 5. Distribución (\%) de respuestas correctas referentes a 'reconocimiento de imágenes' por estamento

\begin{tabular}{|c|c|c|c|c|c|}
\hline \multirow{2}{*}{ Ítem de Reconocimiento } & \multicolumn{5}{|c|}{ Estamento } \\
\hline & Médico & Enfermero (a) & Matrón(a) & Nutricionista & TENS \\
\hline Discriminación imagen 1 & 100 & 100 & 97,1 & 100 & 94,3 \\
\hline Que reconoce imagen 1 & 20,5 & 11,5 & 8,7 & 5,8 & 5,8 \\
\hline Discriminación imagen 2 & 91,2 & 97,1 & 94,1 & 100 & 91,4 \\
\hline Que reconoce imagen 2 & 0 & 0 & 0 & 2,9 & 0 \\
\hline Discriminación imagen 3 & 94,1 & 88,6 & 91,2 & 82,4 & 71,4 \\
\hline Que reconoce imagen 3 & 91,2 & 94,3 & 85,3 & 76,5 & 62,9 \\
\hline Discriminación imagen 4 & 94,1 & 91,4 & 94,1 & 97,1 & 94,3 \\
\hline Que reconoce imagen 4 & 91,2 & 97,1 & 85,3 & 88,2 & 82,9 \\
\hline Discriminación imagen 5 & 100 & 97,1 & 88,2 & 100 & 94,3 \\
\hline Que reconoce imagen 5 & 82,4 & 82,9 & 61,8 & 73,5 & 62,9 \\
\hline Promedio & 76,5 & 76 & 70,5 & 72,6 & 66 \\
\hline
\end{tabular}


azucarados y golosinas con harinas refinadas (11). De ahí se desprende la importancia del ítem de alimentación, donde es posible destacar que ninguno de los estamentos sabe cuándo es propicio retirar el consumo de biberón nocturno, por lo que llegan al control de niño sano odontológico, a los 2 años de edad, aún con este hábito.

Llama la atención que en el estamento de nutricionistas, debido al rol importante que cumplen en la entrega de la dieta para el infante, en las preguntas referentes al uso de azucares, por un lado, y al retiro de biberón nocturno, por otro, se encuentran marcadamente débiles. A esto hay que sumarle el desconocimiento existente del momento de cepillado planteado en el ítem anterior. Esta realidad es posible explicarla en parte debido a que tienen información discrepante con respecto al uso de azúcar en el biberón en la Guía de Alimentación del Niño(a) menor de 2 años (12), que da la posibilidad de complementar calorías en el niño mediante el uso de azúcar.

En cuanto a las anomalías dentomaxilares, salvo las alteraciones congénitas o hereditarias, sus principales causas son los hábitos disfuncionales de succión (chupete o biberón) prolongados erróneamente más allá de la función básica de succión, que, naturalmente, se extingue en forma progresiva a medida que erupcionan los dientes (11). En conocimiento de lo anterior, los estamentos no son capaces de distinguir qué corresponde a un mal hábito y qué a una patología oral; así como tampoco saben qué medidas tomar en este sentido, ni las consecuencias que implica un TDA.

Si se observa la totalidad de los resultados del estudio aplicado al equipo de salud a nivel regional, es posible establecer que promedian un $49 \%$ de respuestas correctas, que en una escala de notas de 1 a 7 , corresponde a nota 3.4; considerando que la nota 4.0, la mínima aprobatoria, se otorga al $60 \%$ de respuestas correctas. En consecuencia, el equipo de salud reprueba sus conocimientos de salud oral, obteniendo una calificación menos que suficiente.

De esta manera, podemos concluir que el instrumento de medición, que se basa en la
Pauta de evaluación buco-dentaria entregada por Minsal el año 2007, ha permitido evaluar el nivel de conocimiento del equipo de salud de los centros de atención primaria de la quinta región, el que ha arrojado un resultado insuficiente.

Además de lo anterior, se debe tener en consideración el sesgo que se pudo haber generado durante la recolección de datos, debido a que, si bien la selección de los centros de atención fue al azar, los participantes fueron escogidos por el director del centro o por el jefe de sector.

Se da por entendido que los centros de atención primaria son el pilar de la salud pública y de la red asistencial en lo que a la promoción y prevención de la salud oral se refiere. De ahí surge la relevancia de investigar y evaluar el conocimiento teórico que manejan los distintos funcionarios del equipo de salud, independientemente de su labor.

Es por eso que este estudio sugiere fortalecer la teoría en el equipo de salud, mediante una mejor integración entre estos y el equipo odontológico, y/o capacitaciones externas. De esta manera se podrá fomentar una nueva cultura de salud bucal, educando a la población materno-infantil en conceptos básicos respecto al valor de la dentadura temporal, la higiene, malos hábitos y alimentación en el niño, haciendo partícipe a cada familia del autocuidado de la salud bucal de sus hijos.

Sin perjuicio de lo anterior, se sugiere llevar a cabo este estudio en otras regiones, e incluso hacerlo extensivo a nivel nacional, con el fin de comparar distintas realidades y/o tener una visión más globalizada respecto de este tema.

\section{REFERENCIAS}

1. Chile. Ministerio de Salud. Orientaciones para la planificación y programación en red año 2013. Chile: Subsecretaría de redes asistenciales, División de Atención de Atención Primaria; 2012, pp. 24-25.

2. Chile. Ministerio de Salud. Reglamento de los Servicios de Salud: Decreto 140 de 2005. Chile: MINSAL; 2005, p. 6. 
3. Conferencia internacional sobre atención primaria de salud, Alma-Ata, URSS, 6-12 de septiembre; 1978.

4. Chile. Ministerio de Salud. En el camino a Centro de Salud Familiar. Chile; Subsecretaría de Redes Asistenciales; 2008. p. 49.

5. Chile. Ministerio de Salud. En el camino a Centro de Salud Familiar. Chile: Subsecretaría de Redes Asistenciales; 2008. p. 69.

6. Chile. Ministerio de Salud. Panta de evaluación buco-dentaria. $2^{a}$ edición. Chile: División de Prevención y Control de Enfermedades. Departamento de Salud Bucal; 2007, p. 3.

7. Pontificia Universidad Católica de Chile. Reglamento del alumno de pregrado: Registros Académicos, Art. 26. Chile: PUC; 2008, p. 6.

8. Ceballos M, Acevedo C, Corsini G, Jans A. Diagnóstico en salud bucal de niños de $2 y$
4 años que asisten a la educación preescolar. Chile: MINSAL; 2007.

9. Soto L, Tapia R, Jara G, Rodríguez G. Diagnóstico Nacional de Salud Bucal del Niño de 6 años. Chile: MINSAL; 2007.

10. Chile. Ministerio de Salud. Pauta de evaluación buco-dentaria. $2^{a}$ edición. Chile: División de Prevención y Control de Enfermedades, Departamento de Salud Bucal; 2007, p. 6.

11. Chile. Ministerio de Salud. Pauta de evaluación buco-dentaria. $2^{a}$ edición. Chile: División de Prevención y Control de Enfermedades, Departamento de Salud Bucal; 2007, p. 5.

12. Chile. Ministerio de Salud. Guía de alimentación del niño(a) menor de dos años. Guia de alimentación hasta la adolescencia: anexo 25. Chile: Departamento nutrición y ciclo vital; 2005. 